\title{
Comunicación intercultural: confrontando concepciones y problemas
}

\author{
Recibido: 02 de diciembre de 2014 \\ Aceptado: 01 de julio de 2015 \\ Publicado: 30 de octubre de 2015
}

\author{
Javier Protzel \\ J.Protzel@up.edu.pe \\ Universidad del Pacífico (Perú)
}

Resumen: Lo intercultural como idea y hecho, tan en boga desde las últimas décadas del siglo pasado gracias a la intensificación de las migraciones internas e internacionales en el mundo, comporta concepciones tan diversas como las culturas prevalecientes en las regiones de intercambio. Estas diferencias privilegian ciertos enfoques e intereses políticos en desmedro de otras, lo cual crea dificultades para que exista una corriente común. Y América Latina ocupa un lugar singular.

Palabras clave: Interculturalidad, investigación, comunicación, lenguas, América Latina.

Abstract: Interculturality, as an idea and as a fact, so present since the last decades of the last century, because of the increasing domestic and international migrations worldwide, entails conceptions which come to be too diverse as the prevailing cultures at the regions of exchange. These differences favor some viewpoints and political interests, disregarding others. This obstructs the generation of shared mainstream. And Latin America holds a singular position therein.

Key words: Interculturality, Research, Communication, Languages, Latin America.

\section{Introducción}

La idea de interculturalidad está ingresando al sentido común a medida que han ido aumentando las interrelaciones entre grupos humanos cuyos modos de vida eran previamente inexistentes y distintos. Ya sean estos encuentros presenciales, ya sean remotos, brindados por los medios de comunicación masivos o mediante el acceso a objetos o prácticas provenientes de lugares distantes y de acervos muy ajenos, la inmensa mayoría de peruanos es consciente de estar viviendo, de un modo u otro, contactos interculturales. 
Sin embargo se trata de una noción cuya ambigüedad va más allá del conocimiento ordinario y de la retórica publicitaria o periodística; es materia pienso yo, de cierta confusión en el mundo académico. Las ópticas adoptadas al abordar temáticas tan vastas han recibido denominaciones tan diversas e incluso contradictorias ("contacto entre civilizaciones", "estudios culturales comparativos", "comunicación intercultural") como lo son las variadas ubicaciones teóricas, culturales y geográficas de quienes las estudian.

Este trabajo propone una reflexión, desde el Perú y Latinoamérica, acerca de cómo el tratamiento de la alteridad cultural ha ido dando un giro substancial en las ciencias sociales y de la comunicación durante las tres últimas décadas. Ello ocurre al planetarizarse los estudios superiores y la investigación, junto con procesos diversos pero comparables de migración, ingreso al mercado y al consumo simbólico de poblaciones anteriormente excluidas en distintas latitudes.

\section{El desarrollo estadounidense del concepto de interculturalidad}

La variedad y mayor volumen de los estudios serían apenas una noticia alentadora si el meollo del asunto no fuese la tensión entre la heterogeneidad de estos contactos y la tendiente estandarización de las investigaciones bajo patrones metodológicos, heurísticos y valorativos comunes. Más acá de los enfoques académicos, el observador o investigador del tema intercultural es inevitablemente un actor situado, vale decir inserto en un lugar y una época desde los cuales se caracteriza a sí mismo y a su relación con los otros.

Pero en esta temática la definición de Ego y Alter es interpelada desde ese estar-situado con mayor claridad que en otras disciplinas de las ciencias sociales. Esto determina ciertos límites epistemológicos impuestos por los marcos cognitivos y los intereses prácticos, lo cual conlleva relativismo, pues los parámetros que fijan lo que es alteridad y alteridad radical varían según quien sea el observador y quién el observado. Así por ejemplo, las diferencias étnicas entre alemanes e inmigrantes turcos que precipitan la xenofobia de algunos de los primeros hacia los últimos serían irrelevantes para la percepción de un latinoamericano en visita a Alemania. Menos relevantes aun le serán las quejas de los turistas estadounidenses respecto al tamaño tan reducido de las habitaciones de los hoteles japoneses. Mucho mayor en cambio es la distancia que separó a los ingenieros de Petroperú de los nativos Awajun y Wampis cuyo conflicto condujo a la masacre de 2009 cerca a Bagua. Alteridad y alteridad radical parecen corresponderse entonces con la oposición entre encuentros simétricos y asimétricos entre grupos culturalmente diferentes.

Recordemos que esto último es señal de una globalización de la movilidad jamás ocurrida, la cual ha ido disminuyendo los aislamientos étnicos y culturales hasta transformar a la humanidad en una totalidad visible y explorable. Con ello, el halo de misterio y peligro que rodeaba a los pueblos lejanos e ignotos se esfuma para el ojo y el pensamiento occidental, mientras las poblaciones urbanas agrupan en 2015 encima de 53\% del total mundial, frente al $29 \%$ de 1950 . La reducción de las rurales es paralela a sus emigraciones a las urbes, sin que a menudo estas les brinden condiciones de supervivencia, obligándoseles a refuncionalizar sus acervos tradicionales. 
De esta suerte las ciudades de crecimiento reciente (en especial del Tercer Mundo) devienen en repositorios culturales vivos por su gran diversidad y complejidad, lo cual ha propiciado una práctica de la antropología urbana a contrapelo de los prejuicios del sentido común, que en vez de trasponer la visión ruralista del trabajo de campo busca construir marcos teórico-metodológicos adecuados para aprehender la densa madeja intercultural urbana; no los de una "[...] antropología en la ciudad [sino de una] antropología de la ciudad" (García Canclini, 1997: 355).

Sin embargo no son muchos quienes se aplican esmeradamente a la antropología urbana. La larga duración de las observaciones etnográficas y las dificultades para el recojo de información favorecen la opción por procedimientos más simples. Hay en cambio sinnúmero de estudios específicos sobre la relación entre culturas desde la década de 1960 (sobre todo en América del Norte y en Asia industrializada) que se aleja de la matriz y de la metodología antropológica. Esta área de la investigación ha sido denominada "comunicación intercultural" , y es incluida en las mallas curriculares de muchos programas académicos de ciencias de la comunicación junto con las asignaturas sobre los medios masivos.

Como su nombre lo indica, su referente es la principal acepción que se da a la comunicación humana, la lingüística, y por una doble razón. Por un lado, el contacto verbal cara a cara suele ser el más frecuente en los encuentros entre nacionales y trabajadores migrantes extranjeros en los países occidentales industrializados. Y por otro, la creciente presencia mundial de los países de la ribera del Pacífico asiático durante los últimos cuarenta años, la cual ha requerido de esfuerzos para cerrar brechas no sólo de abismos lingüísticos sino de diferencias de mentalidad para permitir el mutuo acercamiento de una miríada de interlocutores.

El predominio de universidades japonesas, estadounidenses y chinas en la IAICS es elocuente. Señalemos que esta comunicación intercultural se ejerce en contextos intercontinentales concretos, aquéllos que atañen a viajes de negocio y profesionales, estudiantes en programas de intercambio, pero también a trabajadores migrantes, refugiados. De modo que, pese a su rigor metodológico, la caracteriza su subyacente pragmatismo. Además, los estudios universitarios de comunicación en los Estados Unidos enfatizan la comunicación interpersonal hablada (speech communication). Esta alude a la mutua complementación entre la lengua (materna) y el pensamiento, que según la conocida hipótesis de Edward Sapir y Benjamin Whorf hace que el código lingüístico oriente los procesos de simbolización constituyentes de la cultura o mentalidad de una persona ${ }^{2}$.

1. Una asociación importante que reúne entes académicos en los cuales hay cátedras especializadas y programas de investigación en la materia es la IAICS, International Association for Intercultural Communication Studies (Asociación Internacional de Estudios en Comunicación Intercultural), donde las universidades miembros son en su gran mayoría de Estados Unidos y Asia.

2. El ajuste del entendimiento y percepción de la realidad con la gramática, el léxico y el habla de una persona monolingüe se extiende según la hipótesis Sapir-Whorf a otros sistemas sémicos como los sonidos y la música, los colores, los olores. Es por ello que, según estos dos autores, la lengua es un determinante cultural. 
Una interpretación frecuente de esta hipótesis ha llegado al extremo de postular un relativismo lingüístico que encierra cada pensamiento en la lengua a la cual pertenece y proclama la inconmensurabilidad interlingüística; en otros términos, la imposibilidad de traducir. En cambio, Fernández Casas (2003: 115-129) defiende a Sapir señalando que este, al contrario, considera factible el diálogo entre culturas. Y ese temperamento guía los estudios de comunicación intercultural, tipificada por ser una práctica entre personas o grupos y no entre culturas, una interacción que rebasa la dimensión verbal, sin que toda interacción sea necesariamente intercultural (Levine y otros, 2007: 208-209).

Seguramente esa dimensión de lo no-verbal es el elemento que le ha dado el núcleo teórico que legitimó académicamente a esta disciplina, aunque sus orígenes están ligados a la política exterior de los Estados Unidos. La labor del antropólogo Edward T. Hall (quien prácticamente acuñó el término "comunicación intercultural" durante la década de 1950) consistió en el entrenamiento de los diplomáticos estadounidenses para hacerse comprender adecuadamente y comprender a gente de costumbres y lenguas extrañas que estos trataran en sus misiones de representación (Rogers y otros, 2002: 3-26; LeedsHurwitz, 1990: 262-281).

No pueden dejar de tomarse en consideración las motivaciones geopolíticas que guiaban la labor de Hall en el Foreign Service Institute (Instituto de Servicio en el Extranjero) adscrito al Departamento de Estado. Detrás del propósito de lograr que esos encuentros fuesen armoniosos, subsistía como telón de fondo el rol de potencia hegemónica logrado por los Estados Unidos después de vencer en la Segunda Guerra Mundial, particularmente en el contexto de la Guerra Fría. En 1959 publicó The Silent Language destacaba la importancia de las distintas expresiones del lenguaje no verbal y las diferencias culturales concomitantes a la variedad lingüística. Siete años después apareció The Hidden Dimension ${ }^{4}$, en el cual desarrolló los principios de la proxémica (concepciones y manejo social del espacio), así como afirmó su filiación intelectual al relativismo del antropólogo Franz Boas. También hizo más explícita la relación entre comunicación y cultura, subrayando su opción por definir la comunicación intercultural en base al estudio micro de la interacción entre personas y no el macro de los antropólogos sobre una colectividad analizando otros aspectos como las estructuras de parentesco (Rogers y otros, 2002: 7-8) ${ }^{5}$.

Pese a ello, la elaboración teórica de esta disciplina vino más de un cuarto de siglo después, con la obra de William B. Gudykunst, quien también estuvo al servicio del gobierno de Estados Unidos, a través de la US Navy (Piller, 2011: 30). Su aporte específico fue la investigación y teorización de la incertidumbre y la ansiedad en los encuentros

3. Traducido al castellano y publicado en 1989 en Madrid por Alianza Editorial.

4. Traducido al castellano y publicado en 1972 en México D. F. por Siglo XXI.

5. Hall dejó de lado estos estudios macro a pesar de su formación previa de antropólogo y de su trabajo de campo en Arizona con las comunidades indígenas Hopi y Navajo. Por otro lado, Leeds-Hurwitz (1990: 262-281) ha escrito una reseña intelectual e institucional del Foreign Service Institute que muestra el parentesco entre el pensamiento estratégico estadounidense y la producción de conocimientos útiles. 
entre locales y extranjeros. Partiendo de que no toda comunicación interpersonal con "forasteros" es efectivamente intercultural, esta vertiente busca cómo mejorarla mediante un interaccionismo simbólico que requiere la toma de consciencia acerca de la alteridad (mindfulness) de los interactuantes ${ }^{6}$ (Gudykunst, 2005: 281-332), la cual dará lugar necesariamente a una interpretación por ambas partes (Rodrigo Alsina, 1999: 177-178). Añadamos que Hall había decidido ya anteriormente que para estudiar la comunicación intercultural cara a cara era innecesario conocer una cultura extranjera en su totalidad (Leeds-Hurwitz, 1990: 263).

Constatamos que el énfasis en el contacto verbal, genéricamente cara a cara, urbano y en marcos modernos, señala un divorcio con respecto a la antropología y al vínculo sensorial y cognitivo aportado por el periodismo, la radio y la televisión. No sólo debido a esa reducción o "regionalización" de lo intercultural, sino más bien a su empleo pragmatista, rápidamente aplicado a todo tipo de negocios internacionales y asesorado por profesionales de las relaciones públicas. Es la orientación de las investigaciones de Geert Hofstede (2010) desde la década de 1960 acerca de la relación entre valores y culturas nacionales cuyo paradigma de investigación ha llevado a los Cross Cultural Studies ("estudios culturales comparativos") entre países. Su descomposición de cada cultura nacional, en una variedad de dimensiones sometidas a un análisis factorial para construir indicadores, es sin duda interesante. Los índices de aceptación del poder, de individualismo, de tolerancia a la incertidumbre, de masculinidad, de orientación al largo plazo, y de gratificación diferida permiten elaborar modelos internacionales comparativos, pero ¿hasta qué punto esta practicidad de los indicadores no deja de contener una simplificación del concepto de cultura?

Resulta claro que esa selección de rasgos es pertinente sólo a ciertos fines específicos, como la ubicación de segmentos de población para fines de selección de personal, adaptación de profesionales inmigrantes, negocios internacionales, factibilidad de inversiones, turismo o marketing, dejando de lado al conjunto de una cultura con su densidad y matices. La identificación de cultura con Estados-nación (los "países") es cuando menos dudosa, en la medida en que existen muy pocos de estos últimos en que no se encuentre diversidad y conflicto. Pero mejor expliquémonos seguidamente distinguiendo entre alteridad simétrica y asimétrica. Adelantemos muy en breve que la primera supone encuentros funcionales entre pares para lograr un entendimiento cabal sobre asuntos de interés común, y la segunda se refiere a contactos entre partes muy diferenciadas, separadas al contrario por relaciones de poder muy desiguales y cuyo contacto puede no implicar asuntos de interés común sino discrepancias y conflictos.

6. En su Anxiety / Uncertainty Management Theory ("Teoría de la gestión de la ansiedad y la incertidumbre"), Gudykunst señala que a fin de cuentas en toda interacción hay grados de incertidumbre que logran resolverse mediante el mutuo acuerdo o co-construcción del sentido que requiere tres elementos principales: motivación, conocimiento y destreza. 


\section{Diferencialismo y multiculturalismo}

Una buena parte de la comunicación intercultural de y entre Estados Unidos y Asia se refiere a la primera por las obvias intenciones de comprensión lingüística y no verbal, así como de códigos de comportamiento. Sin embargo, desde una óptica latinoamericana, se constata también que esta disciplina se ejerce principalmente entre ciudadanos de países con una longeva tradición de cultura nacional y de notable integración lingüística y social: Japón, Corea del Sur, Hong Kong y ámbitos industrializados de China, donde el mandarín se ha extendido.

La contrapartida intercultural es generalmente Estados Unidos, país muy ajeno a estos y como sabemos, de una gran diversidad e inmensas fracturas étnicas pero que cuenta con la universalizada lengua inglesa y el acceso al mercado como poderosos factores unificadores que le imprimen su perfil. Ahora bien, la historia cultural estadounidense es la de la hegemonía cultural anglosajona y en la cual, pese a la igualdad ante la ley, sobrevive la segregación hacia los afroamericanos, aunque en versión mitigada. Tomemos nota de que los derechos cívicos les fueron concedidos a los estos apenas en la década de 1960, sin que cambie substancialmente la tensión entre las bajas condiciones materiales de vida de la población negra y los valores anglosajones de ahorro, disciplina y progreso; al contrario, la pobreza y el racismo, más allá de generar problemas de autoestima y anomia, han contribuido a reforzar el espíritu comunitario étnico y sus símbolos (Coontz, 1992: 233).

El modelo fundacional de ciudadanía demoliberal que había cohabitado contradictoriamente con el esclavismo se modificó aun más al calor de las oceánicas migraciones llegadas a Nueva York y San Francisco de fines del siglo XIX a la tercera década del XX ${ }^{7}$. La recepción de chinos, sicilianos, polacos, judíos del Este europeo, armenios, escandinavos, entre otros, por millones amplió la lógica segregacionista en la hasta entonces mayoría anglosajona. El Presidente Theodore Roosevelt mitificó la historia de ese país resaltando la superioridad de los "pueblos de habla inglesa" protagonistas de la avanzada civilizadora hacia las tierras baldías del Oeste que ignoró y exterminó poblaciones indígenas (Shapiro, 1999: 164-166). Discurso épico y expansionista (cristalizado en el cine naciente de cowboys), germen de la ideología neoconservadora actual acerca de una "cultura-núcleo" (Core Culture) basamento de lo "verdaderamente" estadounidense, caracterizada por la lengua inglesa, el acervo anglosajón y los valores readaptados del puritanismo protestante.

\footnotetext{
7 Los picos de inmigración alcanzaron aproximadamente entre 1890 y 1920 su punto más alto, en que según Portes y Rumbaut (2006), los extranjeros eran alrededor del 13.2\% del total de habitantes, mientras que en la actualidad son un poco más del 7\%. Esos inmensos contingentes (mayoritariamente pobres y en muchos casos analfabetos) debían pasar un estricto control sanitario en la isla Ellis antes de poder ingresar a Nueva York a buscar trabajo y fortuna. Estos inmigrantes tuvieron la posibilidad de ser enrolados en calidad de obreros en grandes ciudades como Boston y Chicago, de autoemplearse en pequeños negocios o bien de avanzar hacia el Medio Oeste para la producción agropecuaria, como ocurrió con polacos y escandinavos. Por heterogénea que hubiese parecido entonces esa ola migratoria, no dejaba de estar formada por gentes de origen europeo.
} 
La sociedad blanca dominante, anglosajona y protestante (WASP) se premunió, gracias a su supremacía económica, de una especie de caparazón cultural protectora que la aislaba de ser contaminada; antes por los afroamericanos, y luego por las múltiples proveniencias de los inmigrantes blancos de ultramar, sobre los cuales impuso su hegemonía, no segregándolos sino asimilándolos. Como bien señala Kymlicka (1996), la necesidad de impedir el caos ante tanta diversidad obligó a los migrantes a ceñirse a la "angloconformidad", aceptando el aprendizaje de la lengua inglesa y las costumbres del país. Además, la superioridad de las condiciones de vida fue borrando una parte de las particularidades étnicas de origen (la lengua en segunda generación), lo que daría lugar al mito del "crisol" (Melting Pot) estadounidense.

Al asimilarse bajo condiciones de igualdad los europeos no-anglohablantes se han incorporado a la Core Culture mientras los no-blancos (primordialmente los afrodescendientes y luego los hispanos o "latinos", así como los árabes y asiáticos) han quedado rezagados a la condición de "minorías". Emmanuel Todd, antropólogo francés que ha investigado extensamente este tema, encuentra que en la cultura nacional estadounidense existe un fenómeno llamado "diferencialismo" (différentialisme), cuyas raíces se hunden en épocas muy remotas del territorio de la actual Inglaterra ${ }^{8}$.

Simplificando, el diferencialismo es un concepto antropológico muy importante referido a las estructuras de parentesco. Consiste en considerar a los hermanos desiguales, no sólo para efectos de herencia, sino en que son, substancialmente, diferentes. Se les educa esforzadamente para mantener los méritos del linaje propio, pero sus vocaciones siguen sendas distintas que se pierden en destinos ajenos entre sí. Este tipo de orientación no es consciente para sus actores, pero su funcionamiento se proyecta al resto de la sociedad y a otras áreas de la cultura al transmutarse en una verdadera estructura mental que consagra la no-equivalencia entre las colectividades humanas bajo un principio tajantemente dicotómico Ego/Alter (Todd, 1994: 53-54).

Este autor destaca que a pesar de los esfuerzos estadounidenses en materia de legislación igualitaria, el segregacionismo hacia los afroamericanos (quienes serían antropológicamente los "hermanos diferentes") subsiste, en contraste con la asimilación de los europeos blancos, ya sean estos protestantes, católicos o judíos. Escribe que en el siglo XX funcionó en Estados Unidos

“[...] el mismo mecanismo que hizo posible entre 1630 y 1840 el florecimiento de una democracia en la ausencia de un principio igualitario inscrito en el fondo antropológico. La diferencia negra había permitido olvidar las diferencias entre clases sociales, esta permitió posteriormente el

\footnotetext{
8. La historia de las migraciones británicas es larga, rica y extendida a todo el planeta. Pero en ningún caso la llegada de los anglosajones implicó la mezcla biológica con las poblaciones nativas, desde Massachussets hasta Hong Kong, pasando por Kenya. La población inglesa provino de las migraciones de etnias germánicas ocurridas entre los siglos V y VI de la era cristiana, los anglos, los sajones y los jutos procedentes de las actuales Alemania y Dinamarca (Todd, 1994: 53-54).
} 
borrado de las diferencias familiares y religiosas traídas por los inmigrantes blancos. En suma, la segregación de los negros permitió la asimilación de los blancos"9 (Todd, 1994: 87).

En términos de antropología estructural, el elemento capital es la obsesión dicotómica WASP sumergida en el inconsciente para dividir la realidad entre Ego y Alter, una máquina de simbolizar cuyo engranaje opera implacablemente las categorías inclusión/ exclusión, exterioridad/interioridad y superior/inferior. Todd destaca que las encuestas de opinión estadounidenses muestran un aumento significativo en la población blanca de la desaprobación a la segregación, mientras los hechos les dan un claro desmentido al mantenerse la separación en sus rasgos más visibles: conservación de la endogamia racial (dado el insignificante incremento de miscegenación entre afroamericanos y descendientes de europeos), reticencia de estos últimos a matricular a sus hijos en escuelas mixtas, encierro étnico en ghettos. Para el autor estas señales

\begin{abstract}
“[...] sugieren una eternización del modelo diferencialista americano en el nivel del sistema antropológico. El inconsciente habla, este inconsciente que no cree en la igualdad de los hombres y en la unidad del género humano [...] la sociedad americana nos ofrece el espectáculo asombroso de una disociación mental colectiva, de un conflicto entre consciente e inconsciente colectivo"10 (ibídem: 104).
\end{abstract}

Regresando al ejercicio académico y profesional de la comunicación intercultural, resulta fácil colegir que en la epistemología estadounidense la dicotomía diferencialista funciona como una categoría a priori entre culturas: aun así cohabiten en un mismo territorio, hay "contacto", "encuentro", “diálogo", digamos interfaces sostenidos en lo cognitivo y lo valorativo, pero siempre limitados, sin que se interpenetren entre ellas ${ }^{11}$. Tampoco es casualidad que el ejercicio más abundante de la comunicación intercultural provenga, junto con los Estados Unidos, de países poseedores de lenguas poco habladas fuera de sus fronteras, con estructuras de parentesco rígidamente endógamas, que censuran los matrimonios con extranjeros, tal como ocurre en Japón y Corea del Sur. Pero al tratarse también de países económicamente exitosos, estos se han abierto al mundo y adoptado un habitus cosmopolita cediendo una parte de su acervo anterior, aunque sin renunciar al tabú del mestizaje biológico, clavado en lo profundo de su identidad.

No obstante, el volumen de la población extranjera de origen no europeo (llegada desde fines del siglo pasado a los Estados Unidos y el éxito profesional de muchos de ellos) ha

\footnotetext{
9. Traducción de Javier Protzel.

10. Traducción de Javier Protzel.

11. Existe un modelo de elaboración de una "tercera cultura" propuesto en Estados Unidos, en base a la comunicación intercultural entre individuos de diferentes culturas. Pese a la buena voluntad de quienes lo proponen, se ignora la cuestión del poder (¿quién organiza esos contactos?, ¿en qué lengua?, ¿qué criterios?). Priman la racionalidad occidental, el idealismo y cierto etnocentrismo (Rodrigo Alsina, 1999: 207-217).
} 
conllevado cierta flexibilización: amerindios y asiáticos (japoneses, hindúes, coreanos) están siendo asimilados (Todd, 1994: 95-97), mientras los "latinos" (hispanics) son ellos mismos quienes irónicamente exhiben cierta resistencia a la asimilación, según las estadísticas $^{12}$ de este autor (ibídem: 120-127), sin que por ello ese país se deshaga de una concepción racial de la vida social.

En suma, pese a la multiplicación de la investigación en comunicación intercultural (desde inicios de siglo, debido a la creciente movilidad entre países y a la mundialización de ciertos mercados de consumo, particularmente entre América del norte y Asia) sus ópticas teóricas todavía no le dan un lugar significativo a aquello que, más allá de la comprensión y el conocimiento mutuos, signifique integración, fusión o mezcla. Prueba de ello es el auge del multiculturalismo, aparecido cuando las migraciones transcontinentales arrasaron con el mito del Melting Pot.

El multiculturalismo es la convivencia, bajo el mismo territorio, de grupos pertenecientes a distintas áreas culturales que permanecen relativamente aislados entre sí. Aunque a todos se les puede dar la categoría de ciudadanos, los no europeos difícilmente se libran de la segregación. Esta lógica multicultural, visible también en algunos países europeos, es provocada por la disociación entre identidad cultural y la concepción ilustrada de la ciudadanía.

En la academia estadounidense no dejan de existir críticas y autocríticas a esa corriente dominante (mainstream) de la comunicación intercultural en sociedades de un multiculturalismo de compartimientos estancos. Dos investigadoras de ese país predicen que en el futuro se cuestionará "[...] la noción misma de fronteras culturales", señalando ásperamente que "[...] no hace mucho tiempo el mundo era (¿o todavía es?) 'nosotros' versus 'los salvajes' (a veces 'nobles'). Los otros eran 'demonios extranjeros' o 'bárbaros', y nosotros 'el centro del universo' y de la civilización” (Kim y Hubbard, 2007: 225). Critican el carácter unitario que se atribuye a las culturas nacionales modernas. Es un concepto que a fin de cuentas tiende a "esencializar", es decir, a proclamar la permanencia e inmutabilidad de las tradiciones y mantener unificado aquello que está compuesto por diferencias en una dinámica constante (Friedman, 1995: 80-81). Irónicamente, se convierte en un impedimento para comprender esa dinámica, al extremo de ser no sólo "[...] descriptivamente inservible, sino normativamente peligrosa e insostenible” (Welsch, 1999: 195).

12. En 1980 había unos 14,6 millones de "hispanos" en los Estados Unidos. En 1990 habían aumentado más de 50\%, a 22 millones. En 2013 podía estimarse su número en unos 36 millones. Según señala Todd (1994: 120), el rechazo hacia los mexicanos ha sido comparable al que recibieron los irlandeses y los italianos a fines del siglo XIX y principios del XX. 


\section{América Latina, continente de mezclas}

Pasemos a los escenarios de la alteridad intercultural asimétrica, muy distintos de los ya abordados, y sobre cuya base nos enfocamos en América Latina. Debemos remontarnos muy atrás para detectar un fundamento diferenciador. Ribeiro (1992: 25-31) distinguió la invasión ibérica de la colonización anglosajona, realizadas respectivamente por un imperio "mercantil-salvacionista" y uno "capitalista-mercantil". En su comparación hay dos elementos pertinentes. Primero, las invasiones española y portuguesa fueron alentadas por el afán catequético de conversión de los nativos americanos y por el apetito mercantilista hacia los metales preciosos, propio de esa etapa temprana del capitalismo. Los aventureros de la empresa conquistadora buscaban enriquecerse, darle los tesoros pillados a sus coronas peninsulares y prosiguiendo por otros medios el fanatismo religioso profesado por sus ancestros luchando contra los moros en la tarea de "salvar" las almas paganas de los indígenas. El propósito salvacionista significó sojuzgar a los nativos pero también adoctrinarlos y organizarlos para el trabajo.

Segundo, el celibato forzado del viaje transatlántico los llevó a unirse con mujeres indígenas, del mismo modo en que los esclavos traídos del África no tardaron posteriormente en mezclarse. Por ello, y desde el siglo XVI, el mestizaje biológico fue frecuente en las colonias iberoamericanas, bajo distintas modalidades. Pese a ser poblaciones sometidas y expoliadas, subyacía a estas uniones una implícita igualdad, como ocurrió en la zona andina, donde la miscegenación con las poblaciones indígenas fue temprana. Así fue en el Cusco, pues tal como lo escribió el Inca Garcilaso de la Vega (2012 [1609]: 305) "nos llaman mestizos por decir que somos mezclados de ambas naciones; fue impuesto por los primeros españoles que tuvieron hijos en Indias, y por ser nombre impuesto por nuestros padres"; en el valle del Mantaro (Espinoza Soriano, 1990) o en el Caribe y el Brasil entre europeos, african(a)os e indígenas (Diéguez y Uribe, 1963: 737-738), habida cuenta además del carácter igualitario de las estructuras de parentesco ibéricas.

Pese a la división virreinal de las poblaciones de los países con fuerte componente amerindio en estamentos ("república de españoles" y "república de indios") estas uniones aumentaron a lo largo de más de cuatro siglos sin que la jerarquización étnica dejase de mantenerse. Precisamente lo contrario de los asentamientos puritanos llegados a las costas de Massachusetts de Inglaterra y Holanda en 1609, que incluyeron varones, mujeres y niños, gente educada sin afán ni de conquista ni de contacto con los nativos americanos, pero sí de trabajar la tierra y acumular capital ${ }^{13}$. Además, pese a la virtual falta de contacto con los indígenas de Massachusetts y de Virginia, el aislacionismo anglosajón no fue obstáculo para la importación de esclavos africanos. El diferencialismo se puso en marcha en Virginia y otros Estados, en los cuales las parejas interraciales eran muy escasas hasta formalizarse en 1924, cuando se promulgó la "Ley de Integridad Racial” (Racial Integrity

13. Hagamos sin embargo una salvedad: hubo intentos españoles de colonizar la región de Virginia a mediados del siglo XVI a la cual llamaron Ajacán. Los jesuitas crearon un asentamiento en Ajacán que fue destruido por los naturales, quienes masacraron a todos los misioneros (Lewis y Loomie, 1953). 
Act), que criminalizó los matrimonios interraciales e instituyó la "regla de una gota" (Onedrop Rule $)^{14}$ (Lewis y Loomie, 1953).

En cambio, la interculturalidad resulta ser en la mayor parte de América Latina, menos consecuencia de una "comunicación", "encuentro" o "diálogo" entre compartimientos culturalmente estancos, como lo expuesto más arriba, sino un hecho encarnado y en construcción desde hace siglos. Subrayemos a este respecto dos aspectos característicos, además de la miscegenación.

Por un lado, las relaciones entre culturas fueron asimétricas y conflictivas desde un inicio. No hay necesidad de reseñar la violencia de la invasión ibérica y la magnitud de su agresión física y simbólica, pero sí de constatar cómo las instituciones religiosas, gubernativas y culturales peninsulares se superpusieron a las nativas para generar simbólicas híbridas: las del sincretismo religioso, de mezclas organizacionales entre ayllus o calpullis precolombinos y comunidades campesinas de Castilla y Extremadura, de incorporación de hispanismos al habla quechua, aymará o nahuátl; de cultos africanos creados en el Brasil, integración de narraciones míticas, más un sinfín de fusiones en las artes y las diversas artesanías, tal como lo ha expuesto García Canclini (1992). Esta abundancia intercultural expresa la asimetría de su producción de la que emerge el repertorio simbólico nuevo de una cultura subalterna, pero de resistencia, distinta de la que se asimila a lo ya existente.

Por otro lado, la lógica defensiva de la cultura subalterna de apropiación de los significantes de la cultura dominante ha durado siglos (pintura, música, artesanía, gastronomía) quebrando y subvirtiendo la ortodoxia creativa de sus originales occidentales. Esto le da fluidez y estabilidades variables a estas hibridaciones, puesto que sus contornos van cambiando permanentemente sin quedar claro dónde y cuándo comienzan sus fronteras (Gruzinski, 2000: 295-320). La noción de mestizaje resulta ser equívoca por su generalidad, pues oculta una variedad muy desigual. La imagen ingenua de la interculturalidad (como unión de dos mitades simétricas fusionadas) no resiste en absoluto al análisis, particularmente en México, Perú y Ecuador, países en donde pese a notables avances, la jerarquización étnica (según los grados de miscegenación) mantiene el racismo (Portocarrero, 2013: 2007).

Tomadas ya las distancias frente a la comunicación intercultural, tal como es definido en países desarrollados y cosmopolitas, en América Latina "la idea de interculturalidad ha sido apropiada y reelaborada política, ética y teóricamente por intelectuales, dirigentes y organizaciones indígenas quienes [la] han resignificado" (Mato, 2009: 31). La cuestión intercultural ha ocupado (en países con mayorías de origen indígena y/o afrodescendiente) un lugar destacado en las preocupaciones de antropólogos e historiadores desde mucho antes de que el término fuese acuñado en los Estados Unidos.

14. Según la One-drop Rule las características fenotípicas debían clasificar desde el nacimiento a todos las personas en dos categorías: blancos y de color. La abolición de la Racial Integrity Act no ha impedido que las autoridades de los Estados Unidos sigan clasificando a sus habitantes o visitantes según criterios raciales. 
Sin embargo, los enfoques son muy variados. Por ejemplo, las comunidades negras de la selva colindante a la costa colombiana del Pacífico (descendientes de esclavos fugitivos refugiados) edificaron asentamientos en los cuales reinventaron sus tradiciones africanas bajo una concepción mítica de la naturaleza, por lo cual el Estado colombiano les otorgó la condición de pueblos aborígenes (Rivas, 2004: 327-355; Urrea y Hurtado, 2002: 179). Esto es distinto en la zona más meridional del continente. La anexión del territorio de la nación mapuche en el extremo sur por Chile y Argentina guarda alguna similitud con la "conquista del oeste" norteamericana por su crueldad. En la actualidad, estos países les conceden a los nativos mapuches derechos de ciudadanía multicultural, aunque algunos conflictos subsisten (Ameghino 2013: 171-197). Esto ha sido una sorpresa para la sociedad argentina que ha ido contra su auto-percepción de ser desde siempre un país habitado sólo por descendientes de europeos (Briones y otros, 2007: 266).

En el Perú hay un largo itinerario de la antropología a la interculturalidad. Al elaborar una síntesis ordenada sobre el Perú, Degregori (2008: 19-72) señala que cronistas de la conquista, como Pedro Cieza de León y los curas doctrineros, ya se preguntaban acerca de la inteligibilidad de las culturas nativas al "traducirlas" al castellano. Posteriormente, los viajeros europeos y estadounidenses (desde fines del siglo XVIII hasta la primera mitad del XX), científicos, historiadores y arqueólogos intentaron también comprender y dilucidar incógnitas. Sus miradas, ajenas se cruzaban con las oriundas, como fue el caso del Inca Garcilaso de la Vega, quien se queja de Cieza "por ser español no sabía la lengua tan bien como yo, que soy indio inca" (ibídem: 25).

Pero fue el nacimiento del movimiento indigenista el que marcó el inicio de la antropología. La descripción y análisis del mundo social andino se plasmó en una visión idealizada de las culturas originarias, en especial la quechua, esencializando sus tradiciones y emblemas. Negaba en buena cuenta el componente hispánico e implícitamente rechazaba la hibridación, vale decir, la interculturalidad. El radicalismo indigenista, profesado por las élites cusqueñas de inicios del siglo XX, llegó al extremo de querer imponer un repertorio simbólico neo-incaico cusqueño representativo de lo nacional (De la Cadena, 2004: 61104), en contraposición al hispanismo limeño. En cierto modo, estas luchas ideológicas por definir la identidad nacional pusieron sobre el tapete la pregunta acerca de quién era el Alter cultural, asunto álgido en particular cuando este último está dentro del propio antropólogo (Degregori, 2008: 21).

La abundante literatura antropológica peruana de las décadas de 1960 y 1970 sobre el folclor y las comunidades campesinas osciló entre cierto afán de redescubrir, en el presente, un pasado indígena "auténtico" aun no develado y el reconocimiento de cierto mestizaje modernizante en curso. En todo caso, la antropología post-indigenista añadió dos vías alternas al estudio de las comunidades andinas: a) la comprensión y/o promoción del Alter radical de las comunidades nativas amazónicas y $b$ ) el asesoramiento de pueblos indígenas en sus conflictos territoriales.

En ambos campos, la alteridad se caracteriza por su accidentada situación de acceso o contacto con la modernidad. Las comunidades amazónicas están más aisladas lingüística y materialmente, por lo que se plantea una verdadera necesidad de comunicación intercultural 
para proteger su identidad y favorecer su desarrollo humano. En suma y simplificando, si la sierra y la costa peruanas han devenido en un complejo intercultural moderno, diverso y desigual, en la región amazónica la alteridad es mayor e implica relaciones asimétricas.

\section{Los pueblos amazónicos y sus derechos culturales}

Aunque el interés antropológico por los pueblos amazónicos data de mucho tiempo atrás (Calderón Pacheco, 2000), este aumentó a medida que el contacto social y económico fue poniendo al descubierto (al menos en ciertos medios) los abusos hacia muchos grupos étnicos y permitió valorizar sus acervos. Las problemáticas comunes de exclusión, invasión, depredación de territorios y extracción arbitraria de recursos fueron las razones para que estos grupos unieran fuerzas en 1980 al fundar la AIDESEP (Asociación Interétnica de la Selva Peruana). Esta iniciativa (formada originalmente por amueshas, awajun-huambisas y asháninkas) promueve el derecho a una modernidad compatible con la conservación de sus identidades étnicas, con el uso de la lengua nativa y la continuidad de sus costumbres, así como con la defensa de sus territorios.

El vínculo reside en el caso peruano en la implantación de una educación intercultural bilingüe (EIB) para pueblos indígenas ${ }^{15}$, consistente en el aprendizaje de la lectoescritura en la lengua vernácula materna y no en la castellana, lengua que se aprende después. La mejor comprensión de la realidad y la mejora de la autoestima son un paso hacia adelante, pues esto significa (también para el Ecuador y otros países) una integración nacional basada ya no en "civilizar" a las comunidades nativas, mediante la castellanización, sino en la diversidad. En otros términos, hay una reinterpretación de la identidad nacional que incluye el componente de la pluralidad lingüística en contra de la homogeneización cultural a la cual ha propendido la educación oficial (García, 2008; Zúñiga y Gálvez, 2002: 318).

Los resultados de la educación intercultural no llevan necesariamente a una hibridación, en todo caso a una afirmación de la etnicidad. Realistamente pueden conducir a una situación de bi-culturalidad en la Amazonía ${ }^{16}$, en contraste con la renuencia entre las madres quechuablantes a que sus hijos aprendan la lengua nativa y opten por la asimilación para evitar la estigmatización (Ames, 2002: 348). Por otro lado, la diversidad lingüística tiene un valor patrimonial intrínseco que no deja de estar en peligro, pues en los 53 pueblos indígenas vivos se habla aproximadamente 50 lenguas nativas agrupadas en 14 familias (cifras variables según el criterio de clasificación), de las cuales varias están en peligro de extinción (Ministerio de Cultura, 2013).

15. El término fue creado en un encuentro internacional de pueblos indígenas realizado en Pátzcuaro, México en 1980 (Zúñiga y Gálvez, 2002: 319).

16. Por ejemplo, Sheila Aikman (2003: 157-179) ha mostrado cómo entre los Arakmbut del sudeste amazónico el aprendizaje comprende tres tipos de conocimiento: el del bosque que viene de los espíritus que se encuentra en los sueños, en la narración de mitos impartida por los ancianos, y en la experiencia directa dada por los padres, todo lo cual contrasta con la comunicación impersonal de libro y pizarra de la educación escolar formal. 
Las temáticas de la comunicación intercultural en la Amazonía se amplían y se dramatizan debido a la depredación de sus bosques, en sí una agresión. Huelga detallar que el trasfondo de este tema reside en el interés económico hacia el Perú y otros países del continente de las grandes empresas transnacionales para invertir en actividades extractivas (petróleo, gas, minería, madera). La ruptura del equilibrio ecológico afecta substancialmente a los nativos selváticos por el deterioro irreversible de sus espacios de cultivo, tanto como a las poblaciones andinas, cuyos ríos terminan contaminados por los relaves de mercurio y cianuro.

En esta materia hay pendiente un abundante ejercicio de la comunicación intercultural que va mucho más allá de las diferencias lingüísticas. Por un lado, se trata de hacer respetar los derechos de los pueblos indígenas, y por el otro de persuadirlos acerca de los beneficios materiales obtenibles gracias a la inversión. Como se sabe por los casos de Bagua (Amazonas), Conga (Cajamarca) y Tía María (Arequipa), esta contradicción práctica (entre derechos culturales y racionalidad capitalista) alcanza fácilmente ribetes políticos y desencadena enfrentamientos violentos que interpelan la dimensión simbólica de la parte más débil, que se cohesiona al afirmar su identidad, lo cual aumenta la escalada de intransigencia entre las partes.

Los pueblos indígenas amazónicos cuentan con la protección del Convenio 169 sobre Pueblos Indígenas y Tribales en Países Independientes de la Organización Internacional del Trabajo (OIT) firmado en 1989, que somete a una consulta previa las inversiones que fuesen a realizarse dentro de territorios ancestrales amerindios. Esto frecuentemente no ocurre, por más que los pueblos nativos consideren sagrados a los espacios que ocupan. Las normas internas autónomas, la adscripción territorial y las creencias míticas generan una tirantez constante con los Estados nacionales (Tovar, 2007: 119-137).

Al contrario, en la mayor parte de la sierra andina peruana no se aplica el Convenio 169, en virtud de que la mayoría de sus habitantes no habla una lengua vernácula, requisito antropológico estándar para caracterizar a una identidad indígena. No obstante, un estudio de Benavides y Valdivia (2004: 4-5) señala que el criterio para definirla se ha establecido en base a la lengua que declaran hablar el jefe de familia o su pareja al ser censados. Este criterio, uno entre otros, ha arrojado un $17 \%$ de familias indígenas a escala nacional. Pero ocurre que cuando se consultó sobre la lengua de los antepasados, el porcentaje se elevó a $48 \%$, casi la mitad de los peruanos.

Es evidente que el retroceso del quechua en la región andina es una señal de incomodidad con respecto a las imágenes tradicionales de la condición indígena, mal avenidas con las promesas de la modernidad y portadoras de estigmas. ¿Es selectiva la supresión de ciertos marcadores simbólicos (lengua, acento, vestimenta, música, dieta) manteniendo una misma identidad, o bien se trata de un progresivo cambio, perceptible sólo al comparar lapsos extensos de tiempo? Probablemente, en el largo plazo, se trate de un proceso de asimilación desigual a la mentalidad cosmopolita de la modernidad tardía, con diferencias saltantes en Cusco y Puno, pero sin que el racismo cese. Lo cual permite afirmar que una sociedad intercultural, como la peruana, no es más tolerante e igualitaria. En cambio, los 
pueblos amazónicos sí pueden estar ante la oportunidad de desarrollar una convivencia multicultural con la modernidad, si los vientos políticos les son favorables.

El mestizaje que José María Arguedas elogió cuando residió en Huancayo (así como el que Manuel Pardo y José de la Riva Agüero vieron con entusiasmo al visitar el valle del Mantaro varias generaciones antes) parecería estarse decolorando. Era más una promesa y no una realidad. Lo real está en un cambio moral, visible en el crecimiento de la familia monoparental, la individuación y los estímulos que impelen a satisfacer un nuevo ego. Este hace suyos los estilos de vida ofrecidos a chorros por las industrias culturales, así como el afán de dinero por cualquier medio como horizonte único, que ha ido haciendo perder de vista el espíritu comunitario y el clima de armonía al que los autores mencionados aludieron. La emigración serrana a la selva también comporta contactos culturales, aunque este es de un daño a los nativos que cunde de narcotráfico, tala de madera y minería de oro (ambas ilegales), prostitución y crimen organizado.

“Cada ser humano tiene un 'resto no culturizado' que le permite trascender su propio universo cultural y hace posible el diálogo con otros desde una identidad siempre en proceso" (López Soria, 2006). El requisito para que ese resto se trascienda y genere una dinámica intercultural efectiva es la reciprocidad de los distintos ethos que se tocan y hacen contacto, es decir una dimensión moral.

\section{Fuentes consultadas}

Aikman, S. (2002). "Women's oral knowledge and the poverty of formal education in the SE Peruvian Amazon”. Gender and Development. Vol. 10, núm. 3, pp. 41-50.

Ameghino, N. (2013). "Un pueblo, dos Estados: participación Mapuche en el Estado. Los casos de Argentina y Chile". Sí somos americanos. Revista de Estudios Transfronterizos. Vol. 3, núm. 1, pp. 171-197.

Ames, P. (2002) "Educación e interculturalidad: repensando mitos, identidades y proyectos", pp. 343-371. En Fuller, N. (ed.). Interculturalidad y política. Desafíos y posibilidades. Lima: Red para el Desarrollo de las Ciencias Sociales en el Perú.

Benavides, M. y Valdivia, M. (2004). Metas del milenio y la brecha étnica en el Perú. Versión preliminar. Lima: GRADE. Extraída el 4/VIII/2015 desde http://www.grade.org. pe/download/ docs/informe\%20ethnicity\%20and\%20MDGs\%20v3.pdf

Briones, C. y otros (2007). "Escenas del multiculturalismo neoliberal. Una proyección desde el Sur”, pp. 265-299. En Grimson, A. (ed.) Cultura y neoliberalismo. Buenos Aires: CLACSO.

Calderón Pacheco, L. (2000). "Imágenes de Otredad y frontera. Antropología y pueblos amazónicos”, pp. 238-277. En Degregori, C. (ed.). No hay país más diverso. Compendio de antropología peruana. Lima: IEP. 
Coontz, S. (1992). The Way We Never Were. American Families and the Nostalgia Trap. Nueva York: Basic Books.

Degregori, C. (2008). "Dilemas y tendencias en la antropología peruana: del paradigma indigenista al paradigma intercultural”, pp. 19-72. En Degregori, C. y Sandoval, P. (eds.). Saberes periféricos. Ensayos sobre la antropología en América Latina. Lima: IFEA, IEP.

De la Cadena, M. (2004). Indígenas mestizos. Raza y cultura en el Cusco. Lima: IEP.

Diéguez, M. y Uribe, O. (1963). "El Brasil como proceso de mestizaje y transculturación". Revista Mexicana de Sociología. Vol. 25, núm. 2, pp. 737-745.

Espinoza Soriano, W. (1990). La destrucción del Imperio de los Incas. La rivalidad política y señorial de los curacazgos andinos. Lima: Amaru.

Friedman, J. (1995). “Global System, Globalization and the Parameters of Modernity”, pp. 69-91. En Featherstone, M.; Lash, S. y Robertson, R. (eds.). Global Modernities. Londres: Sage.

Fernández Casas, M. (2003). "El relativismo lingüístico en la obra de Edward Sapir. Una revisión de tópicos infundados”. Revista Teorema. Vol. XXII, núm. 3, pp. 115-129.

García Canclini, N.

(1997). "Urban cultures at the End of the Century: The Anthropological Perspective". International Social Science Journal. Vol. 49, núm. 153, pp. 345-356.

_(1992). Culturas híbridas. Estrategias para entrar y salir de la modernidad. Buenos Aires: Sudamericana.

García, M. (2008). Desafios de la interculturalidad. Educación, desarrollo e identidades indígenas en el Perú. Lima: IEP.

Garcilaso Inca de la Vega (2012 [1609]). Comentarios Reales [vol. 2]. Barcelona: Lingkuadigital.

Gruzinski, S. (2000). El pensamiento mestizo. Barcelona: Paidós.

Gudykunst, W. (2005). Theorizing about Intercultural Communication. Thousand Oaks. California: Sage.

Hofstede, G.; Hofstede, G. J. y Minkov, M. (2010). Cultures and Organizations: Software of the Mind. Nueva York: McGraw-Hill.

Kim, M. y Hubbard, S. (2007). "Intercultural Communication in the Global Village. How to understand 'The Other'". Journal of Intercultural Communication Research, Vol. 36, núm. 3, pp. 223-235. 
Kymlicka, W. (1996). Ciudadanía multicultural. Una teoría liberal de los derechos de las minorías. Barcelona: Paidós.

Leeds-Hurwitz, W. (1990). "Notes on the history of intercultural communication: The Foreign Service Institute and the Mandate for Intercultural Training". Quarterly Journal of Speech, núm. 76, pp. 262-281.

Levine, T. y otros (2007). "Some Conceptual and Theoretical Challenges for Cross-Cultural Communication Research in the 21st Century". Journal of Intercultural Communication Research. Vol. 36, núm. 3, pp. 205-221.

Lewis, C. y Loomie, A. (1953). The Spanish Jesuit Mission in Virginia, 1570-1572. Chapel Hill: North Carlona University Press.

López Soria, J. (2006). “Filosofía e interculturalidad” Ponencia presentada en el II Congreso Iberoamericano de Filosofía. Lima, PUCP.

Mato, D. (2009). "Conceptos, contextualizaciones y usos de la idea de interculturalidad". En Aguilar, M. y otros (eds.). Pensar lo contemporáneo: de la cultura situada a la convergencia tecnológica. México D. F.: Anthopos, UAM Iztapalapa.

Ministerio de Cultura del Perú (2013). "Base de datos de pueblos indígenas u originarios". Extraída el 4/VIII/2015 desde http://bdpi.cultura.gob.pe/lista-de-pueblos-indigenas

Piller, I. (2011). Intercultural Communication. A Critical Introduction. Edimburgo: Edinburgh University Press.

Portes, A. y Rumbaut, R. (2006). Inmigrant America: A Portrait. California: University of California Press.

Portocarrero, G.

_(2013). "La utopía del blanqueamiento y la lucha por el mestizaje”, pp. 165-200. En Portocarrero, G. (ed.) Sombras coloniales y globalización en el Perú de hoy. Lima: Red Peruana para el Desarrollo de las Ciencias Sociales.

_(2007). Racismo y mestizaje y otros ensayos. Lima: Fondo Editorial del Congreso de la República.

Ribeiro, D. (1992). Las Américas y la civilización. Proceso de formación de causas y desarrollo desigual de los pueblos americanos. Caracas: Biblioteca Ayacucho.

Rivas, N. (2004). “Ambientalismo surgimiento de nuevos actores étnicos en el Pacífico Sur”, pp. 327-358. En Barbary, O. y Urrea, F. (eds.). Gente negra en Colombia. Dinámicas sociopolíticas en Cali y el Pacifico. Medellín: Cidse, Ird, Colciencias.

Rodrigo Alsina, M. (1999). Comunicación intercultural. Barcelona: Anthropos. 
Rogers, E.; Hart, W. y Miike, Y. (2002) "Edward T. Hall and the History of Intercultural Communication: the United States and Japan”. Keio Communication Review, núm. 24. Extraída el 14/VIII/2015 desde http://www.mediacom.keio.ac.jp/publication/pdf2002/ review24/2.pdf

Shapiro, J. (1999). "Triumphalist Geographies. The Winning of the West", pp. 160-175. En Featherstone, M. y Lash, S. (eds.). Spaces of Culture. City, Nation, World. Londres: Sage.

Todd, E. (1994). Le destin des immigrés. Assimilation et ségrégation dans les démocraties occidentales. París: Éditions du Seuil.

Tovar, M. (2007). "Régimen sociopolítico de los pueblos indígenas: democracia, ciudadanía y comunidad”, pp. 119-138. En Brunelle, D. (ed.). Gobernabilidad y democracia en las Américas. Loja: Universidad Técnica Particular de Loja.

Welsch, W. (1999). “Transculturality: The Puzzling Form of Cultures Today”, pp. 194-213. En Featherstone, M y Lash, S. (eds.). Spaces of Culture. City, Nation, World. Londres: Sage.

Urrea, F. y Hurtado, T. (2002). "La construcción de las etnicidades en la sociedad colombiana: un caso ejemplar para una discusión sobre etnicidad y grupos raciales", pp. 165-199. En Fuller, N. (ed.). Interculturalidad y política. Desafios y posibilidades. Lima: PUCP, UP, IEP, Red para el desarrollo de las Ciencias Sociales en el Perú.

Zúñiga, M. y Gálvez, M. (2002). "Repensando la educación bilingüe intercultural en el Perú: bases para una propuesta política”. Pp. 309-330. En Fuller, N. (ed.). Interculturalidad y política. Desafios y posibilidades. Lima: Red para el Desarrollo de las Ciencias Sociales en el Perú. 